\title{
O PRINCÍPIO DO DESENVOLVIMENTO SUSTENTÁVEL E SUAS IMPLICAÇÕES JURÍDICO-SOCIAIS
}

\author{
Anelise Coelho Nunes* \\ Cíntia Schmidt**
}

Todo princípio, como fonte do Direito, fundamenta o sistema jurídico a fim de mantê-lo como um todo lógico e coeso, organizado a partir da hierarquia axiológica das fontes.

A partir disso, infere-se que o princípio do desenvolvimento sustentável tem apresentação não só como fonte do Direito brasileiro - mais precisamente no Direito ambiental - mas também como norma constitucional, e, assim, embasa tanto o sistema quanto o ordenamento jurídico, já que encontra-se insculpido na norma do artigo 225 da Lei Maior.

Como norma constitucional, detém posição hierarquicamente superior em relação às demais normas do ordenamento jurídico, gozando do status da supremacia das normas constitucionais, pela lição kelseniana.

Em vista dessas considerações, registre-se que a denominação do princípio do desenvolvimento sustentável surgiu, inicialmente, com a Conferência Mundial do Meio Ambiente, realizada

* Doutora em Direito (PUCRS). Professora Universitária. Advogada.

** Mestra em Direito (PUCRS). Professora Universitária. Advogada. Docente do Centro Universitário Metodista IPA. 
em 1972 em Estocolmo e novamente utilizada nas conferências que se sucederam, como a ECO-92, realizada no Brasil.

Tal princípio busca harmonizar a atividade econômica e o meio ambiente, uma vez que a primeira se vale de recursos ambientais, normalmente utilizados como matérias-primas, os quais não são inesgotáveis. Portanto, o desenvolvimento deve ocorrer, mas de modo que a sustentabilidade preserve os recursos ambientais.

Hodiernamente, a degradação ambiental consiste em uma problemática que atinge o mundo todo, e demanda, necessariamente, a fim de que seja encontrada uma solução não-paliativa, uma ação em todos os níveis: regionais, nacionais, globais. Impõe-se a necessidade de estabelecer diversas forma de promover o desenvolvimento sustentável - o que exige uma mudança nos hábitos e nas atitudes das pessoas.

A conscientização ambiental está muito aquém do desejado, eis que as fragilidades do mercado não levam em consideração a variável ambiental em muitos casos, caracterizando, dessa forma, um desenvolvimento irracional e não-sustentável.

Em 1972, a Organização das Nações Unidas patrocinou a Conferência das Nações Unidas sobre Meio Ambiente Humano (Conferência de Estocolmo), resultando em uma declaração de princípios e critérios de comportamento e responsabilidade que deveriam governar as decisões concernentes a questões ambientais. Na referida Conferência, concluiu-se que os princípios de conservação ambiental eram incorporados ao desenvolvimento, originando-se o termo "ecodesenvolvimento", ou seja, o desenvolvimento em nível regional e local, atendendo as potencialidades da área em tela, dando atenção ao uso adequado e racional dos recursos naturais e à aplicação de novas tecnologias apropriadas, além do respeito aos ecossistemas naturais, objetivando a utilização de recursos, de acordo com as necessidades humanas e melhoria e manutenção da qualidade de vida humana para esta geração e as futuras. 
Posteriormente, a Assembleia Geral das Nações Unidas, em 1983, aprovou a criação de uma Comissão Mundial sobre Meio Ambiente e Desenvolvimento, tendo à frente da presidência dos trabalhos a ex-primeira ministra da Noruega, Gro Harlem Bruntland. A comissão era constituída ainda por representantes de dez países desenvolvidos e dez países em desenvolvimento. Após três anos de trabalhos, a referida Comissão publicou o relatório que ficou conhecido como Relatório Brundtland, apontando os principais problemas ambientais, sendo divididos em três grandes grupos:

1. Poluição ambiental, emissões de carbono e mudanças climáticas, poluição da atmosfera, poluição da água, dos efeitos nocivos dos produtos químicos e dos rejeitos nocivos, dos rejeitos radioativos e a poluição das águas interiores e costeiras;

2. Diminuição dos recursos naturais, como a diminuição das florestas, perdas de recursos genéticos, perda de pasto, erosão do solo e desertificação, mau uso de energia, uso deficiente das águas de superfície, diminuição e degradação das águas freáticas, diminuição dos recursos vivos do mar;

3. Problemas de natureza social tais como: uso da terra e sua ocupação, abrigo, suprimento de água, serviços sanitários, sociais e educativos e a administração do crescimento urbano acelerado.

A partir de então, a expressão "desenvolvimento sustentável" ganhou notoriedade. 0 princípio, contido na ideia de desenvolvimento sustentável, exprime o direito que os seres humanos têm a uma vida saudável, em harmonia com o ambiente, satisfazendo as necessidades das gerações presentes, sem comprometer as necessidades das gerações futuras.

Este princípio constitucional reflete o reconhecimento do direito fundamental ao meio ambiente ecologicamente equilibrado, devendo a proteção ambiental ser considerada parte integrante 
do processo de desenvolvimento, levando-se em consideração a variável ambiental no processo de tomada de decisões.

Na norma do artigo 225 da Constituição Federal de 1988, o princípio encontra-se descrito da seguinte forma: "todos têm direito ao meio ambiente ecologicamente equilibrado..., impondo-se ao Poder Público e à coletividade o dever de defendê-lo e preservá-lo para as presentes e futuras gerações" (grifo nosso).

Quanto ao conteúdo do princípio, importante lição cabe registrar (FIORILLO; DIAFÉRIA, 1999):

Dessa forma, o princípio do desenvolvimento sustentável tem por conteúdo a manutenção das bases vitais da produção e reprodução do homem e de suas atividades, garantindo igualmente uma relação satisfatória entre os homens e destes com o seu ambiente, para que as futuras gerações também tenham oportunidade de desfrutar os mesmos recursos que temos hoje a nossa disposição.

Enfatiza-se a importância da consideração da variável ambiental no processo de tomada de decisões e, por consequência, adota-se o princípio da prevenção, através do qual os danos ambientais podem ser minimizados nas atividades que se têm conhecimento do seu impacto, e, por sua vez, o princípio da precaução, naquelas atividades ou experimentos do que ainda não se tem todo o conhecimento necessário, imperando-se tomar extrema cautela, muito cuidado, de forma antecipada, com o que ainda não se tem ciência, e, assim, buscar o desenvolvimento sustentável.

O desenvolvimento sustentável introduz intencionalmente o paradigma axiológico e existencial da sociedade homeostática, que precisa reunir os seguintes aspectos nucleares: (a) é determinação ética e jurídico-institucional, oriunda diretamente da Constituição, de responsabilização de todos pelos direitos presentes e futuros ao ambiente qualificadamente sadio e favorável ao bem-estar, monitorado por metas e indicadores 
viáveis; (b) é determinação ética e jurídico-institucional da responsabilidade objetiva pela prevenção e precaução, de maneira que se chegue antes dos eventos danosos, à semelhança do que sucede nos dispositivos antecipatórios biológicos; (c) é determinação ética e jurídico-institucional de sindicabilidade aprofundada das escolhas públicas e privadas, de sorte a evitar cautelarmente mitos comuns, armadilhas falaciosas e políticas inconsistentes, com o dever de promoção segura e concomitante do desenvolvimento material e imaterial (valorativo e sutil); (d) é determinação ética e jurídico-institucional de responsabilidade pela educação ambiental, voltada ao desenvolvimento de baixo carbono, compatível com os valores supremos da Carta, que não se confundem com os do crescimento material, considerado como fim em si. Ou seja, uma reeducação valorativa "esverdeada" é ponto de destaque em qualquer programa constitucional, digna do nome. (FREITAS, 2011)

0 referido autor, ao conceituar o termo "sustentabilidade", assevera que ele

É o princípio constitucional que determina, independentemente de regulamentação legal, com eficácia direta e imediata, a responsabilidade do Estado e da sociedade pela concretização solidária do desenvolvimento material e imaterial, socialmente inclusivo, durável e equânime, ambientalmente limpo, inovador, ético e eficiente, no intuito de assegurar, preferencialmente de modo preventivo e precavido, no presente e no futuro, o direito ao bem-estar físico, psíquico e espiritual, com consonância homeostática com o bem de todos.

Após o Relatório de Brundtland, ficou constatada a necessidade de uma nova Conferência Internacional, com o condão da discussão da temática ambiental, abrindo caminho para a Conferência do Rio de Janeiro (ECO/92 ou Rio/92). 
Verifica-se que houve uma evolução, caminhando para uma sustentabilidade efetiva, mas ainda está muito lenta diante da degradação que foi causada no Planeta Terra. Percebe-se, assim, que o desenvolvimento econômico está cada vez mais atrelado às preocupações universais de proteção ambiental, já que os recursos naturais devem ser preservados sob pena de extinção.

Diante disso, as empresas, gradativamente, estão investindo em tecnologias menos poluidoras, adotando filtros e outras técnicas menos agressivas, procurando minimizar os impactos ambientais - ações que demonstram que a ideia e a preocupação com o desenvolvimento sustentável tem sido absorvida pela sociedade, ainda que gradualmente.

Nesse sentido, segundo dados disponíveis no site do Instituto de Altos Estudos de Direito Público, de acordo com o relatório, lançado em 2011, pelo PNUMA (Programa das Nações Unidas do Meio Ambiente), investir dois por cento do PIB mundial em dez setores estratégicos pode ser o "pontapé inicial" para a transição rumo a uma Economia Verde de baixo carbono e eficiência de recursos.

Apoiada por políticas nacionais e internacionais inovadoras, a soma, que atualmente correspondente a cerca de 1,3 trilhão de dólares por ano, fomentaria o crescimento da economia global a níveis provavelmente superiores aos dos atuais modelos econômicos.

0 relatório sugere um modelo econômico que evitaria riscos, choques, escassez e crises cada vez mais inerentes na atual economia de alta emissão de carbono.

Sendo assim, contesta os mitos de que investimentos ambientais vão contra o crescimento econômico, trazendo à tona a má alocação de capital.

0 relatório mostra a Economia Verde como um tema relevante não apenas para as economias mais desenvolvidas, mas também, como um catalisador-chave para o crescimento e a erradicação da pobreza nas economias em desenvolvimento, 
nas quais, em alguns casos, cerca de $90 \%$ do PIB está ligado à natureza ou a recursos naturais, como a água potável.

0 relatório também traz como exemplo resultados de políticas que redirecionam cerca de 1,3 trilhão de dólares por ano em investimentos verdes e, por meio de dez setores estratégicos, o equivalente a aproximadamente $2 \%$ do PIB mundial.

Em termos comparativos, esse montante equivale a $10 \%$ do investimento total anual em capital físico.

Atualmente, o mundo gasta entre $1 \%$ e $2 \%$ do PIB global em uma série de subsídios que, no geral, prolongam a insustentabilidade do uso de recursos, tais como combustíveis fósseis, agricultura, água e pesca. Tem-se que mudar este quadro de modo urgente.

Impende ressaltar que o desenvolvimento sustentável possui previsão no Princípio $4^{\circ}$ da ECO/92: “A fim de alcançar o desenvolvimento sustentável, a proteção do ambiente deverá constituir-se como parte integrante do processo de desenvolvimento e não poderá ser considerada de forma isolada".

Então, para o desenvolvimento das políticas públicas, relativas ao aproveitamento dos recursos naturais, por meio do exercício do poder soberano estatal, há que se seguir os preceitos de responsabilidade e do interesse público, não se limitando apenas às presentes gerações, mas também às futuras, como os incentivos fiscais para novas fontes energéticas menos poluentes, como a energia solar e eólica, por exemplo.

Segundo Juarez Freitas, a sustentabilidade é princípio jurídico, correspondendo a um princípio de estatura constitucional, com a densificação infraconstitucional (FREITAS, 2011). Também é um princípio que se consorcia com os princípios constitucionais da prevenção e da precaução. 0 autor finaliza sugerindo que, afinal, se o desenvolvimento aparece de modo expresso na Constituição, a sustentabilidade desponta como um princípio constitucional-síntese, porque o único desenvolvimento que interessa é aquele que se constitui mutuamente com a sustentabilidade. 
Concorda-se com o referido posicionamento, tendo em vista que a Constituição Federal menciona expressamente o desenvolvimento e, ademais, não se pode conceber outra interpretação tópico-sistemática que não conceba a expressão do desenvolvimento sustentável, justamente para dar lógica, coesão e organicidade ao sistema jurídico, diante da concepção do desenvolvimento sustentável como princípio.

Então, para o desenvolvimento das políticas públicas relativas ao aproveitamento dos recursos naturais, através do exercício do poder soberano estatal, há que serem seguidos os preceitos de responsabilidade e do interesse público, visando à coletividade, cuidando-se do ambiente e não se limitando tão-somente às presentes gerações, mas, também, às futuras.

A população necessita de um novo modelo de progresso que associe o desenvolvimento econômico, o social e o ambiente em um agir de forma ética, pois devem andar lado a lado e, não, como antagonistas.

Somente a partir do planejamento adequado das políticas públicas é que poderão ser reconhecidos os contornos da sustentabilidade, a fim de propiciar o equilíbrio entre o crescimento econômico, o desenvolvimento social e a utilização dos recursos naturais, mediante a integração da decisão econômica pela questão ambiental.

Neste contexto, ingressam as novas preocupações em relação ao bem-estar da sociedade de risco, devendo-se implementar políticas socioambientais, preconizando sempre o desenvolvimento sustentável, já que a "preservação ambiental e o desenvolvimento econômico devem coexistir, de modo que aquela não acarrete a anulação deste" (FIORILLO, 2011).

Essas novas preocupações fizeram com que as atividades econômicas e seu régio princípio - a livre iniciativa - passassem a sofrer limitações, em prol do bem comum, a partir da determinação do princípio constitucional da defesa do meio ambiente, 
elencado na norma do inciso VI do art. 170 da Constituição Federal de 1988, a qual dispõe:

Art. 170. A ordem econômica, fundada na valorização do trabalho humano e na livre iniciativa, tem por fim assegurar a todos existência digna, conforme os ditames da justiça social, observados os seguintes princípios:

(...)

IV - defesa do meio ambiente, inclusive mediante tratamento diferenciado conforme o impacto ambiental dos produtos e serviços e de seus processos de elaboração e prestação.

A existência digna preconizada no caput da norma constitucional importa em vida com qualidade, na dignidade da pessoa humana compreendida como fundamento da ordem constitucional brasileira, a partir de sua relação intrínseca com os direitos fundamentais.

A dignidade da pessoa humana deve ser interpretada como o metaprincípio do sistema jurídico brasileiro (BONAVIDES, 2011). Ela atua como o alfa e o ômega do sistema de liberdades constitucionais e dos direitos fundamentais (SARLET, 2010).

Portanto, a vinculação da aplicação do desenvolvimento sustentável à dignidade da pessoa humana necessariamente perpassa pela limitação da atuação econômica em vista do princípio da defesa do meio ambiente, ao que Luiz Alberto David Araújo refere:

A inserção desse princípio (defesa do meio ambiente) significa que nenhuma indústria que venha deteriorar o meio ambiente pode ser instalada? A resposta é negativa. A eficácia da norma consiste em fixar uma interpretação que leve à proteção ao meio ambiente. Todo o esforço da ordem econômica deve ser voltado para a proteção do meio ambiente, ao lado de outros valores citados no art. 170, em seus incisos. (ARAÚJO, 1992) 
Dessa forma, o princípio do desenvolvimento sustentável é caracterizado pelo desenvolvimento que atenda às necessidades do presente, sem comprometer as futuras gerações.

No entanto, há quem critique a expressão "desenvolvimento sustentável", como Leonardo Boff. Para ele, "desenvolvimento provém da área da economia dominante. Já sustentabilidade provém da biologia. São expressões contraditórias e inconciliáveis. Há pensadores que preferem a expressão sociedade sustentável ou retirada sustentável."(TRIGUEIRO, 2009)

Muito embora seja interessante a possibilidade do uso da expressão "sociedade sustentável", discorda-se da impossibilidade de conciliação e discordância entre desenvolvimento e sustentabilidade, uma vez que propugna-se pela opção do uso de todas as expressões referidas, pois, cada uma em seu contexto próprio vai abarcar ideias distintas. Assim como "retirada sustentável" indubitavelmente refere-se à retirada de recursos da natureza, de modo sustentável.

De qualquer forma, o desenvolvimento sustentável como valor constitucional é referencial ao sistema jurídico.

E é claro que, apesar de todo aporte jurídico que o desenvolvimento sustentável congrega, há a necessidade de que a sociedade também o imprima como princípio fundamental, diante de mudanças comportamentais.

E tal possibilidade só existe diante de um liame forte entre sustentabilidade e educação para o desenvolvimento.

Dizer que a educação é prioridade, de fato, virou clichê, com a força empobrecida e empoeirada dos lugares comuns. Já reconhecer que existe uma diretriz constitucional, com aplicabilidade direta e imediata, que obriga o Estado a garantir a formação geradora de bem-estar durável, a ponto de o Poder Judiciário determinar a matrícula de criança em creche, introduz avanço significativo, na densificação da sustentabilidade multidimensional. (FREITAS, 2011) 
A sustentabilidade demanda abordagens pedagógicas inovadoras, das quais Juarez Freitas estabelece quatro premissas: a visão de causalidade de longo prazo, a visão de pluridimensionalidade do desenvolvimento, a visão da sustentabilidade como causa poderosa e a visão da sustentabilidade como fonte de homeostase (FREITAS, 2011).

Na visão de causalidade de longo prazo, a educação de boa qualidade multidimensional é aquela que entende a repercussão das condutas como engrenagens da causalidade, de modo positivo ou negativo, com a propagação dos efeitos consequentes.

Já na visão de pluridimensionalidade do desenvolvimento, a educação precisa observar o desenvolvimento em seus mais variados aspectos (ético, social, econômico, ambiental e jurídico-político), de modo a preparar para a vida e o crescimento.

A visão da sustentabilidade como causa poderosa, por seu turno, determina que a educação mobiliza e é mobilizada quando vê a sustentabilidade como uma causa forte, ocupando nobre espaço em nossas mentes.

Finalmente, a visão da sustentabilidade como fonte de homeostase, impõe trabalhar seriamente, deliberadamente pela homeostase, "como capacidade biológica e institucional de promover o reequilíbrio dinâmico e propício ao bem-estar duradouro". (FREITAS, 2011)

Portanto, a educação, para além das ações de comando e controle, voltada para o desenvolvimento duradouro, tem de ser processada desde a infância (FREITAS, 2011).

Mudanças comportamentais apenas serão incorporadas pela sociedade se, através da educação, houver o reconhecimento da importância do desenvolvimento sustentável, da sustentabilidade como questão cotidiana na vida das pessoas, como a coleta seletiva de lixo, pois é justamente a partir de que pequenos gestos que, somados aos dos outros, fazem toda a diferença. 
E é somente a partir da valoração social que o fato jurídico tem seu razão de ser, pois não basta o desenvolvimento sustentável integrar o conteúdo das fontes do direito, como princípio, e não estar respaldado na sociedade, caso não seja aplicado.

Portanto, o desenvolvimento sustentável importa em existência digna, ao atendimento do "metaprincípio" do sistema jurídico brasileiro, da dignidade da pessoa humana, mas deve ter sua função instrutiva bem definida a fim de que sirva de paradigma, para a defesa e a preservação do meio ambiente para as presentes e para as futuras gerações.

\section{REFERÊNCIAS}

ARAÚJO, Luiz Alberto David. Direito constitucional e meio ambiente. Revista do Advogado da AASP, São Paulo, 37:67, 1992

BONAVIDES, Paulo. Curso de Direito Constitucional. 26a. ed. São Paulo: Saraiva, 2011

BRASIL. Constituição da República Federativa do Brasil. Congresso Nacional, 1988.

FIORILlo, Celso Antonio Pacheco. Curso de direito ambiental brasileiro. 12a. ed. São Paulo: Saraiva, 2011

FIORILLO, Celso Antonio Pacheco; DIAFÉRIA, Adriana. Biodiversidade e patrimônio genético no direito ambiental brasileiro. São Paulo: Max Limonad, 1999

FREITAS, Juarez. Sustentabilidade: direito ao futuro. Belo Horizonte: Fórum, 2011

INSTITUTO BRASILEIRO DE ALTOS ESTUDOS DE DIREITO PÚBLICO. Direito ambiental: rumo à economia verde. Disponível em: <http:// www.altosestudos.com.br/?p=47428>. Acesso em: 20 set. 2011.

SARLET, Ingo Wolfgang. A dignidade da pessoa humana na Constituição Federal de 1988. 10a. ed. Porto Alegre: Livraria do Advogado Editora, 2010

TRIGUEIRO, André. Espiritismo e ecologia. São Paulo: Feb, 2009. 